\title{
Hypogonadism as a possible link between metabolic diseases and erectile dysfunction in aging men
}

\author{
Giovanni Corona, ${ }^{1}$ Silvia Bianchini, ${ }^{1}$ Alessandra Sforza, ${ }^{1}$ Linda Vignozzi, ${ }^{2}$ Mario Maggi ${ }^{2}$ \\ ${ }^{1}$ Endocrinology Unit, Maggiore-Bellaria Hospital, Medical Department, Azienda-Usl Bologna, Bologna; ${ }^{2}$ Sexual Medicine \\ and Andrology Unit, Department of Experimental, Clinical and Biomedical Sciences, University of Florence, Florence; Italy
}

\begin{abstract}
There is evidence demonstrating that sexual complaints represent the most specific symptoms associated with late onset hypogonadism, while central obesity is the most specific sign. In obese men, hypogonadism can further worsen the metabolic profile and increase abdominal fat. In addition, although hypogonadism can exacerbate obesity-associated erectile dysfunction (ED), recent data suggest that a direct contribution of fat-derived factors could be hypothesized. In particular, an animal model recently documented that fat accumulation induces several hepatic pro-inflammatory genes closely linked to corpora cavernosa endothelial dysfunction. Lifestyle modifications and weight loss are the first steps in the treatment of ED patients with obesity or metabolic diseases. In symptomatic hypogonadal men with metabolic impairment and obesity, combining the effect of testosterone substitution with lifestyle modifications could result in better outcomes.
\end{abstract}

Key words: Erectile dysfunction, Metabolic syndrome, Obesity, Testosterone

\section{INTRODUCTION}

Several population-based surveys have documented that in men testosterone $(\mathrm{T})$ levels progressively decline with age..$^{1-5}$ In particular, according to the European Male Aging Study (EMAS), a survey of more than 3400 community-dwelling, middle-aged and older men, after the third decade $\mathrm{T}$ decreases by $0.4-2 \%$ per year. ${ }^{5}$ The specific mechanisms underlying this

\section{Address for correspondence:}

Prof. Mario Maggi, Sexual Medicine and Andrology Unit,

Department of Experimental, Clinical and Biomedical Sciences,

University of Florence, Florence, Italy; Viale Pieraccini 6, 50139

Florence, Italy; Tel.: +39-55-4271415, Fax: +39-55-4271413,

E-mail: m.maggi@dfc.unifi.it

Received: 27-08-2015, Accepted: 05-10-2015 phenomenon have not been completely clarified but age-related associated morbidities rather than aging per se seem to play a major role. ${ }^{5,6}$

Different $\mathrm{T}$ thresholds have been proposed for the biochemical definition of low $\mathrm{T}^{7,8}$ in aging men, also known as late onset hypogonadism (LOH). The most widely shared consensus ${ }^{7,8}$ is that $\mathrm{T}$ substitution may be beneficial when circulating total $\mathrm{T}$ is below $8 \mathrm{nmol} / \mathrm{L}(231 \mathrm{ng} / \mathrm{dL})$ in two measurements. Moreover, there is also general agreement that a total $\mathrm{T}$ level above $12 \mathrm{nmol} / \mathrm{L}$ (346 ng/dL) does not require substitution. There is in addition a consensus that a reduction of $\mathrm{T}$ is not sufficient to define a clinically relevant hypogonadal state, especially in the "gray area", with circulating T between 8 and $12 \mathrm{nmol} / \mathrm{L} .{ }^{7,8}$ 
Hence, to define $\mathrm{LOH}$, specific hypogonadism-related symptoms and signs should also be present. ${ }^{7-10}$ Data from the EMAS survey clearly demonstrated that sexual symptoms, in particular low libido and reduced spontaneous and sex-related erections, represent the most specific symptoms associated with low $\mathrm{T}$ (total $\mathrm{T}$ level of less than $11 \mathrm{nmol} / \mathrm{L}$ and a free $\mathrm{T}$ (FT) level of less than $0.225 \mathrm{nmol} / \mathrm{L}){ }^{11}$

In line with this evidence, in male subjects consulting for sexual dysfunction, in contrast to other forms of male hypogonadism, $\mathrm{LOH}$ is a relatively common condition. Figure 1 shows the prevalence of symptomatic $\mathrm{LOH}$ in the general population of Florence, one of the participating centers in the EMAS survey, according to age intervals. By using the strict EMAS criteria, the prevalence of $\mathrm{LOH}$ in Florence increases from being quite an unusual condition in the younger age groups to more than $3 \%$ in the oldest one. In the same figure, using the same diagnostic criteria, the prevalence of $\mathrm{LOH}$ in subjects seeking medical care at an andrology unit for sexual dysfunction at the University of Florence (UNIFI) - hence from the same geographic area - is reported. It is evident that in subjects complaining of sexual dysfunction $\mathrm{LOH}$ is 5 times more prevalent than in the general population.

A large body of evidence has demonstrated that although sexual complaints represent the most specific

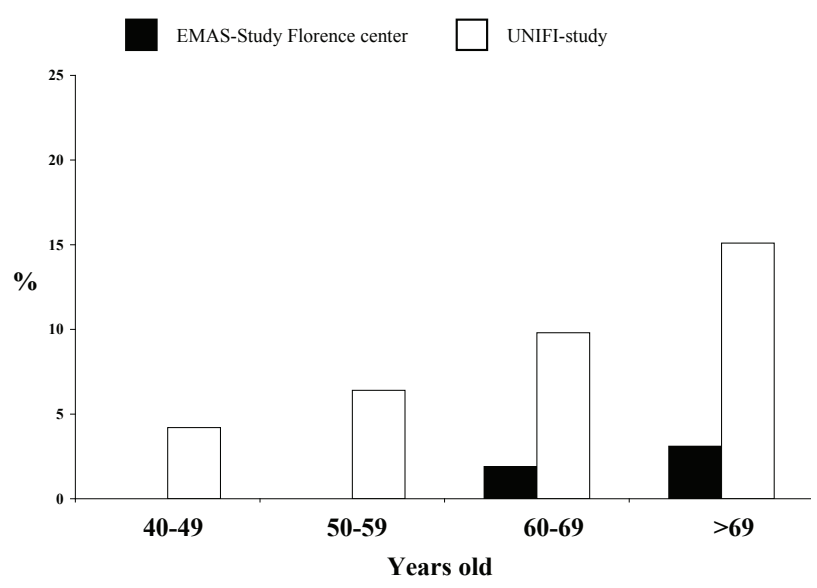

Figure 1. Prevalence of hypogonadism according to the European Male Aging Study (EMAS) criteria (11) in Florentine subjects of the EMAS survey $(n=433)$ and in a consecutive series of $(n=3293)$ output-patients receiving medical care for sexual dysfunction between 2000-2011 at our center (UNIFI study; 10). symptoms associated with $\mathrm{LOH}$, central obesity is the most specific sign. ${ }^{7,8,12-14}$ Obesity (and in particular central obesity-related complications) is also a wellrecognized risk factor for erectile dysfunction. ${ }^{15,16}$ Although obesity related metabolic and cardiovascular (CV) complications have been proposed as playing a major pathogenetic role, recent studies have also suggested a direct contribution of several visceral fat-derived factors including chemokines, cytokines and hormones in the pathogenesis of $\mathrm{ED}^{17}$ (see for review 15,16).

In this review, we will analyze in depth the relationship between obesity, its metabolic complications and male hypogonadism $(\mathrm{HG})$, and their contribution to the pathogenesis of ED.

\section{METABOLIC IMPAIRMENT AND HYPOGONADISM: A BIDIRECTIONAL LINK CONTRIBUTING TO ED}

\section{Clinical evidence}

The association between $\mathrm{LOH}$, obesity, metabolic syndrome (MetS), insulin resistance and type 2 diabetes (T2DM) is well known. ${ }^{7,8,14,18,19}$ In two independent meta-analyses of the available evidence, we have reported that subjects with MetS and T2DM have significantly reduced $\mathrm{T}$ levels (about $3 \mathrm{nmol} / \mathrm{l}$ lower). ${ }^{21,22}$ These data were more recently confirmed in subjects with MetS by Brand et $\mathrm{a}^{23}$ and Zumoff et $\mathrm{al},{ }^{24}$ and we ourselves ${ }^{25}$ previously showed an inverse correlation between body mass index (BMI) and both total and free $T$. In addition, this feature was not associated with an adequate increase in luteinizing hormone (LH) levels, suggesting the presence of obesity-related pituitary impairment response (Figure 2). In accord with this data morbidly obese men indicate that $\mathrm{LH}$ levels and pulse amplitude were attenuated when compared to normal weight controls. ${ }^{26,27}$ Similarly, a recent study indicates that in subjects with T2DM there is a decreased gonadotropin-releasing hormone (GnRH) pulsatility without significant change in pituitary sensitivity to GnRH or in testis sensitivity to human chorionic gonadotropin. ${ }^{28}$

Longitudinal analysis of data suggested, however, the presence of a bidirectional link between obesity and low T. In fact, although low $\mathrm{T}$ at baseline increased 


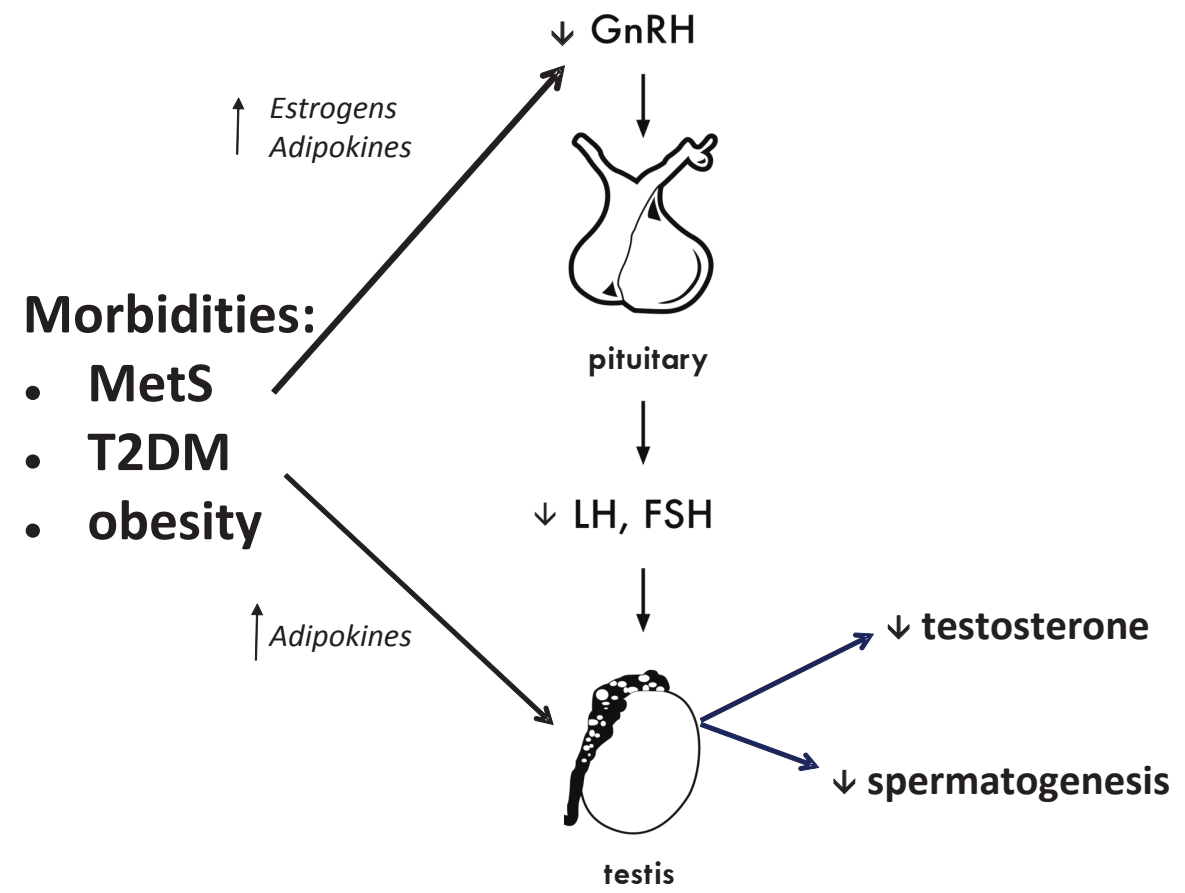

Figure 2. Proposed interactions between increased visceral fat and hypogonadism. MetS: metabolic syndrome; T2DM: type 2 diabetes mellitus; LH: luteinizing hormone; FSH: follicle stimulating hormone. GnRH: gonadotropin releasing hormone; T: testosterone.

the risk of T2DM and MetS at follow up ${ }^{21-23}$ the opposite phenomenon has also been documented. ${ }^{14,18}$ Similarly, longitudinal data from the EMAS survey showed that weight gain was progressively associated with a decline in $\mathrm{T}$ levels, whereas weight loss was proportionately associated with increases in $\mathrm{T} .{ }^{29}$

By comparing the prevalence of endocrine abnormalities in two different cohorts from the general (Florentine spin-off of the EMAS cohort; $n=202$ ) and the symptomatic populations of Florence (a series of $n=3847$ patients attending our clinic for ED; UNIFI cohort), we recently reported that secondary hypogonadism as well as central obesity (waist $>102$ $\mathrm{cm}$ ), impaired fasting glucose (IFG) and T2DM were more often detected in UNIFI patients when compared to the EMAS cohort. ${ }^{30}$ Hence, our data confirm that ED populations represent a cohort of subjects with increased incidence of metabolic abnormalities and hypogonadism. It is conceivable that central obesityassociated hypogonadism might partially justify this association. However, our analyses indicated that the association between central obesity and ED in the UNIFI cohort was confirmed even after the adjustment for T levels and BMI, suggesting a direct role of central obesity in the pathogenies of ED. In line with this hypothesis, we previously reported that the association between ED and central obesity was independent of known obesity-associated comorbidities (including hypogonadism) and was more strongly linked to an organic than to psychological and relational problems. ${ }^{15}$ Similar results were reported by the EMAS survey. ${ }^{31}$ Longitudinal data confirmed that obesity and central obesity at baseline were the most important predictors for the development of secondary hypogonadism at follow up. ${ }^{31}$ However, incident secondary hypogonadism was associated, independently of BMI, comorbidities and lifestyle, with new or worsening sexual symptoms but not physical or psychological ones. ${ }^{31}$

\section{Preclinical evidence}

The specific pathogenetic mechanisms linking $\mathrm{LOH}$ with obesity and metabolic derangements appear to be complex and are not as yet completely understood (Figure 2). The presence of a hypothalamus-pituitary pathway impairment seems to represent the key feature. Several adipokines (e.g. leptin), cytokines (e.g. tumor necrosis factor- $\alpha$; TNF $\alpha$ ) and gastrointestinal hormones (e.g. ghrelin), along with increased estrogen 
production by the expanded fat deposits, have been suggested as causing the gonadotropin failure. , $^{142-34}$ One of the most intriguing working hypotheses is related to the role played by estrogens (Figure 2). The increased estrogen levels, which characterize obesity, might in turn have a negative effect on both the hypothalamus and the pituitary, leading to decreased LH secretion. ${ }^{14,32-34}$ Accordingly, the use of the aromatase inhibitor letrozole can restore $\mathrm{T}$ levels and increase LH levels in severely obese hypogonadal men. ${ }^{35}$ Similarly, body weight loss, obtained through either lifestyle or bariatric intervention, is associated with a fall in estrogen levels and with a rise in gonadotropins and T. ${ }^{36}$ However, the role of estrogens in reducing GnRH-gonadotropin secretion has not been confirmed in obese diabetic ${ }^{23}$ and non-diabetic men. ${ }^{6}$ Hence, besides estrogens, other fat-associated factors have been proposed as a link between obesity and reproductive axis disorders (Figure 2). In fact, obesity may cause peripheral and central insulin resistance, pro-inflammatory cytokine production (TNF $\alpha$ and interleukin-6, IL-6) from adipocytes and central nervous system endocannabinoid release that can induce down-regulation of hypothalamic function. ${ }^{14,31}$ In an animal model of MetS, we previously reported that increased visceral fat and the overall MetS condition, and in particular the related altered glucose and lipid metabolism, were associated with hypothalamic inflammation and derangement in the neuron network controlling GnRH release..$^{32,33,38} \mathrm{In}$ addition, it is possible that peripheral metabolic derangements, such as those clustered in the MetS, signal to the hypothalamus via increased local inflammation and via a glucose-centered down-regulation of the neuronal network controlling GnRH release. In fact, recent findings demonstrated that a subpopulation of GnRH neurons projects dendrites into regions outside the blood brain barrier, where they may directly sense molecules circulating in the bloodstream. ${ }^{39}$ Using a well characterized cellular model, we identified a direct inhibitory action of increasing glucose concentrations on human fetal GnRH-secreting neurons, the FNC-B4 cells. ${ }^{32}$ In line with this hypothesis, we recently reported that in subjects with ED almost $3 / 4$ of cases of the unknown causes of hypogonadism can be attributed to metabolic abnormalities including obesity and MetS. ${ }^{40}$
Furthermore, established hypogonadism might also worsen obesity. In vitro studies indicate that androgens inhibit adipogenic differentiation of mouse or human preadipocytes (rPAD) through an androgen receptor (AR)-mediated pathway. ${ }^{41,42}$ In addition, we demonstrated that high-fat-diet (HFD)-induced hypogonadism in rabbits determines the impairment of several cellular abnormalities in rPAD, including a reduced ability of triglyceride synthesis, glucose uptake, protein kinase B (AKT) phosphorylation and glucose transporter type 4 (GLUT4) membrane translocation, as well as by the reduced expression of adipogenic genes. ${ }^{43,44}$

Despite the specific mechanisms linking obesity and hypogonadism, our experimental data support the view of a direct role of obesity in the pathogenesis of ED. In fact, the strong association between visceral adiposity and impaired acetylcholine-induced relaxation in the corpora cavernosa (CC) was not explained by any metabolic or hormonal alteration considered. ${ }^{15}$ In a further study by our group, ${ }^{17}$ we demonstrated that in an animal model diet-induced visceral-fat accumulation was associated with nonalcoholic steatohepatitis (NASH) and that several hepatic pro-inflammatory genes were closely linked to $\mathrm{CC}$ endothelial dysfunction (acetylcholine responsiveness). In particular, we proposed that NASH plays an active role in the pathogenesis of ED through TNF $\alpha .{ }^{17}$

\section{Interventional evidence}

\section{Lifestyle modifications}

According to all recommendations, lifestyle modifications should be the usual first-line approach for all patients. In fact, there is a good deal of evidence documenting that in individuals at risk, intensive lifestyle interventions, along with nutritional counseling and physical activity, are able to reduce weight and insulin resistance, thus preventing the progression of obesity to other diseases, such as overt diabetes and CV disease. ${ }^{45-49}$

Interestingly, meta-analyzing available evidence, we recently demonstrated that weight loss is also able to increase $\mathrm{T}$ levels proportionately related to the amount of reduction in body weight. ${ }^{36}$ In addition, in the same study we observed a weight loss-dependent increase in SHBG, calculated FT (cFT), LH and 
follicle stimulating-hormone (FSH) and a reduction in estradiol. However, multiple regression analysis showed that the degree of body weight lost was the best determinant of total $\mathrm{T}$ rise $(\mathrm{B}=2.50 \pm 0.98, \mathrm{P}=0.029)$, whereas no effect of estradiol decrease after weight loss on total $\mathrm{T}$ was observed. ${ }^{36}$ These data confirm that other fat-associated factors, besides estrogens, can be speculated as mediating obesity associated hypogonadism.

The increase in the amount of physical activity should be an essential component of the lifestyle modifications. ${ }^{45-49}$ According to World Health Organization recommendations (http://whqlibdoc.who.int/ publications/2010/9789241599979_eng.pdf) adults aged 18-64 years should do at least 150 minutes of moderate-intensity aerobic physical activity throughout the week, or at least 75 minutes of vigorous-intensity aerobic physical activity throughout the week, or an equivalent combination of moderate- and vigorousintensity activity. A recent meta-analysis including 47 studies demonstrated that sedentary behavior in adults significantly increased the risk of all-cause mortality, CVD and cancer mortality and incidence as well as T2DM incidence. ${ }^{50}$ Interestingly, a recent randomized controlled trial (RCT) showed that resistance training might have an acute effect on $\mathrm{T}$ production and clearance rates, while the exercise-induced increases in serum $\mathrm{T}$ appeared to come about through decreased metabolic clearance rate of $\mathrm{T}^{51}$

In line with what has been observed for all the aforementioned conditions, lifestyle modification and maintaining an active lifestyle in men resulted in improvement even in ED. ${ }^{52}$ A systematic review and meta-analysis of six RCTs evaluating the effect of lifestyle interventions and pharmacotherapy for $\mathrm{CV}$ on the severity of ED demonstrated an overall significant improvement in sexual function, which was confirmed even when only trials of lifestyle change interventions $(\mathrm{n}=4)$ were considered. ${ }^{53}$

\section{Testosterone therapy}

Despite previous evidence, it should be recognized that everyday clinical practice has shown that diet and behavioral therapies often ultimately fail. In fact, from $60 \%$ to $86 \%$ of weight lost is regained after 3 years and $75 \%-121 \%$ after 5 years. ${ }^{54}$ A meta-analysis including 65 primary qualitative studies on the topic of dietary modification challenges encountered by patients with T2DM and/or heart disease reported that common challenges in these subjects include selfdiscipline, knowledge, coping with everyday stress, negotiating with family members and managing the social significance of food. This report also confirms that despite health care provider recommendations encouraging people at risk to change their diet, many patients find it difficult to modify what they eat..$^{55}$

$\mathrm{T}$ is an anabolic hormone and its effects on muscle growth and function are well known. Recently, some observational studies in men with $\mathrm{LOH}$ reported substantial weight loss with T substitution. ${ }^{56-58}$ Hence, the concept of testosterone supplementation (TS) as a new anti-obesity medication in men with $\mathrm{LOH}$ is gaining ground. ${ }^{14,18,59-61}$ On the other hand, TS is able to improve sexual function in hypogonadal (total $\mathrm{T}$ $<12 \mathrm{nM}$ ) men. ${ }^{61,62}$ Therefore, $\mathrm{T}$ could be used in association with lifestyle intervention in hypogonadal men to improve metabolic and sexual outcomes. In this section, the metabolic and sexual effects of TS will be analyzed in greater detail.

\section{TS and metabolic outcomes}

The anti-obesity activity of TS in hypogonadal men may be effective because, on the one hand, it reduces abdominal fat accumulation and, on the other, it improves muscle mass and strength, facilitating adherence to exercise regimens designed to combat obesity. ${ }^{14,18}$

Only a few RCTs have evaluated the impact of TS in patients with MetS and T2DM. By meta-analyzing available evidence, we found that TS was associated with a significant reduction of fasting glycemia, HOMA index, triglyceride levels and waist circumference (WC) in patients with MetS. ${ }^{10}$ Correspondingly, an improvement of fasting glycemia, $\mathrm{HbAlc}$ and triglyceride levels was observed in subjects with T2DM. ${ }^{10}$ To further understand the possible role of TS in body composition and glycometabolic profile in hypogonadal men, we more recently performed a meta-analysis of all RCTs comparing the effect of TS on different metabolic endpoints. ${ }^{63}$ Overall, 59 trials were included in the study enrolling 3029 and 2049 subjects in the TS and control groups, respectively. No significant modification of body weight, WC and BMI was detected. However, TS was associated with 
a significant reduction of fat and with an increase of lean mass as well as with a reduction of fasting glycemia and homeostasis model assessment (HOMA) index (Table 1). Similar results were observed for total cholesterol and triglyceride levels when only RCTs enrolling hypogonadal (total $\mathrm{T}<12 \mathrm{~mol} / \mathrm{L}$ ) subjects were considered (Table 1). Conversely, no improvement in high density lipoprotein (HDL) cholesterol levels or in either systolic or diastolic blood pressure was observed (Table 1). In addition, the outcomes were better in younger individuals and in those with metabolic diseases. ${ }^{63}$ Finally, when the data were analyzed according to the type of $\mathrm{T}$ preparation used, no improvement in body composition (both lean and fat mass modification) and glycemic control was observed in those trials using oral $\mathrm{T}$ preparations, whereas the use of both transdermal and parenteral preparations were effective with the application of the latter drugs resulting in better outcomes..$^{63}$ The observed improvement in glucose metabolism can be ascribed to either increased muscle mass or to decreased fat mass. However, our data suggest that

Table 1. Mean difference or mean standardized differences in several clinical parameters after testosterone substitution as derived from meta-analysis of the available evidence (adapted from ref.\# 63)

\begin{tabular}{lc}
\hline Clinical parameter & Outcome \\
\hline Body composition & $0.43[-0.54 ; 1.39]$ \\
Weight $(\mathrm{kg})$ & $-0.66[-2.66 ; 1.35]$ \\
Body Mass Index $\left(\mathrm{kg} / \mathrm{m}^{2}\right)$ & $0.25[-0.09 ; 0.58]$ \\
Waist circumferences $(\mathrm{cm})$ & $-0.32[-0.44 ;-0.19]^{* *}$ \\
Fat mass (standardised mean) & $0.51[0.37 ; 0.66]^{* *}$ \\
Lean mass (standardised mean) & \\
Glucose profile & $-0.34[-0.51 ;-0.17]^{* *}$ \\
Fasting glycemia $(\mathrm{mM})$ & $-0.80[-1.16 ;-0.45]^{* *}$ \\
HOMA index & \\
Lipid profile & $-0.357[-0.61 ;-0.13]^{* * \S}$ \\
Total cholesterol $(\mathrm{mM})$ & $-0.22[-0.37 ;-0.08]^{* \S}$ \\
Triglycerides $(\mathrm{mM})$ & $-0.03[-0.08 ; 0.01]$ \\
HDL cholesterol $(\mathrm{mM})$ &
\end{tabular}

Blood pressure

Systolic blood pressure $(\mathrm{mmHg})$

$0.94[-1.08 ; 2.96]$

Diastolic blood pressure $(\mathrm{mmHg})$

$0.95[-0.66 ; 2.54]$

${ }^{*} \mathrm{p}<0.05,{ }^{*} \mathrm{p}<0.0001 ;{ }^{\S}$ only studies enrolling hypogonadal (total testosterone $<12 \mathrm{nM}$ ) subjects were considered. HDL: high density lipoprotein; RCT: randomized controlled trial. increased muscle mass is most probably responsible for the more favorable glucose metabolism associated with TS. In fact, the positive associations between T levels, glycemia and HOMA-IR index were confirmed in a multivariate model after adjusting for lean, but not fat, mass. ${ }^{63}$ Similarly, in an experimental model of MetS-associated hypogonadism, obtained by feeding rabbits a high-fat diet, we demonstrated that $\mathrm{T}$ administration was able to dramatically reduce visceral adiposity and, in cultured adipocytes, to increase insulin sensitivity and triglyceride metabolism. ${ }^{43}$ Hence, our data show that TS might help hypogonadal individuals in changing body composition, glucose metabolism, and, possibly, weight.

Considering the positive action of TS on body composition, and in particular on muscle mass and strength, it is possible that in established hypogonadal obese men, combining the effect of TS with lifestyle modifications could result in better outcomes. So far, five RCTs ${ }^{64-68}$ have specifically evaluated the effect of a combined therapy with TS and lifestyle modification on HG-associated metabolic derangements and body composition. Overall, the available RCTs enrolled 243 patients, with a mean follow-up of 36.8 weeks. By meta-analyzing these subjects we recently reported that the combination of TS and lifestyle modifications is able to produce better outcomes than lifestyle behaviors alone, including the improvement of body composition (reduction of WC and fat mass and increase in lean mass), lipid profile (reduction of triglycerides levels), insulin resistance (reduction of insulin levels and HOMA index) and diastolic blood pressure (Table 2). ${ }^{18}$

\section{TS and sexual function}

The effects of TS on male sexual functions in ED subjects are still very controversial. ${ }^{69,70}$ Another controversial issue is the effect of TS on phosphodiesterase type 5 (PDE5) inhibitor (PDE5i) outcomes. ${ }^{70-72}$ A substantial improvement in the response to PDE5is was seen in $37.5-92 \%$ of these men following a combination of T therapy with PDE5is..$^{70-72}$ However, data on placebo controlled RCTs are more conflicting. ${ }^{73-76}$

We recently reported the largest, updated metaanalysis evaluating the effect of TS on male sexual function and its synergism with the use of PDE5is in RCTs comparing the effect of TS vs. placebo or the 
Table 2. Mean difference or mean standardized differences in several clinical parameters across randomized controlled trials evaluating the effect of testosterone substitution alone or in combination with low calorie diet and/or physical exercise. Data are presented as derived from the non-paired analysis (adapted from ref.\# 18)

\begin{tabular}{lc}
\hline Clinical parameter & Outcome \\
\hline Body composition & \\
Waist circumferences (cm) & $-7.11[-11.12 ;-3.11]^{* *}$ \\
Fat mass (standardised mean) & $-1.24[-2.31 ;-0.17]^{*}$ \\
Lean mass (standardised mean) & $1.47[0.81 ; 2.13]^{* *}$ \\
Glucose profile & \\
Fasting glycemia (mM) & $-7.51[-13.19 ;-1.83]^{*}$ \\
HOMA index & $-1.80[-3.31 ;-0.29]^{*}$ \\
Lipid profile & \\
Triglycerides (mM) & $-0.37[-0.68 ;-0.06]^{*}$ \\
Blood pressure & \\
Diastolic blood pressure $(\mathrm{mmHg})$ & $-1.53[-2.48 ;-0.57]^{* *}$ \\
\hline *p<0.05, **p<0.0001. &
\end{tabular}

effect of TS as an add-on to PDE5is. ${ }^{62}$ Overall, 41 RCTs were included in the study, of which 29 compared TS vs. placebo, while 12 trials evaluated the effect of TS as an add-on to PDE5is. Our data clearly indicated that TS is able to significantly ameliorate erectile function and to improve, in hypogonadal men $(\mathrm{TT}<12 \mathrm{nM})$, other aspects of male sexual response, including sexual desire and orgasm, as well as several other sexual parameters, including nocturnal erection, frequency of intercourse, overall sexual satisfaction and overall sexual function (Table 3 ).

Our study, however, was not able to clarify the role of TS as an add-on to PDE5is in the treatment of ED subjects. In fact, although a positive effect was observed in uncontrolled studies, the results were not confirmed when only RCTs were considered. The lack of benefits in RCTs may suggest the uselessness of TS as an adjunctive therapy to PDE5is in ED patients. However, it should be recognized that 3 out of $5^{73-75}$ of the aforementioned RCTs enrolled a population of mixed eugonadal/hypogonadal subjects at baseline. In addition, in Spitzer's large trial, ${ }^{76}$ although only hypogonadal subjects were enrolled at baseline, TS was initiated after a sildenafil alone run-in period, leading to $\mathrm{T}$ increase up to the normal range (about $12.0 \mathrm{nmol} / \mathrm{L}$ ). Similarly, it has previously been reported that sexual inertia is associated with functional hypo-
Table 3. Effect size (with 95\% confidence interval [CI]) in several sexual parameters across randomized controlled trials evaluating the effect of testosterone substitution vs. placebo (adapted from ref.\# 62)

Sexual parameter Outcome

\section{Erectile function component}

Overall erectile function component ${ }^{\S} \quad 0.82[0.47 ; 1.17]^{*}$

Overall sexual-related function $\quad 0.75[0.37 ; 1.12]^{* *}$

component $^{\S \S}$

Sleep-related erections

$0.87[0.47 ; 1.27]^{* *}$

Libido component

Overall libido component

$0.81[0.47 ; 1.17]^{* *}$

Orgasm component

Overall orgasmic component $\quad 0.68[0.34 ; 1.02]^{* *}$

Other sexual parameters

Frequency of intercourse

Overall sexual satisfaction

$0.75[0.33 ; 1.16]^{* *}$

Overall sexual function

$0.80[0.41 ; 1.20]^{* *}$

${ }^{*} \mathrm{p}<0.001,{ }^{*} \mathrm{p}<0.0001 .{ }^{\S}$ including coital and non coital erections;

$\S \S$ only coital erections considered.

gonadotropic hypogonadism which can be restored accompanied by improvement of sexual activity. ${ }^{77-81}$

\section{CONCLUSION}

Hypogonadism represents one of the several complications of obesity and T2DM in men. In these men, hypogonadism can further worsen the metabolic profile and increase abdominal fat. Sexual symptoms are the most specific symptoms associated with hypogonadism in aging men. Although hypogonadism can exacerbate obesity-associated $\mathrm{ED}$, recent data suggest that a direct contribution of fat derived factors could be hypothesized. Lifestyle modifications and weight loss are the first steps for ED patients with obesity or metabolic diseases. In symptomatic hypogonadal men with metabolic impairment and obesity, combining the effect of testosterone substitution with lifestyle modifications could result in better outcomes.

\section{REFERENCES}

1. Gray A, Feldman HA, McKinlay JB, Longcope C, 1991 Age, disease, and changing sex hormone levels in middle-aged men: results of the Massachusetts Male Aging Study. J Clin Endocrinol Metab 73: 1016-1025.

2. Ferrini RL, Barrett-Connor E, 1998 Sex hormones and 
age: a cross-sectional study of testosterone and estradiol and their bioavailable fractions in community-dwelling men. Am J Epidemiol 147: 750-754.

3. Harman SM, Metter EJ, Tobin JD, Pearson J, Blackman MR; Baltimore Longitudinal Study of Aging, 2001 Longitudinal effects of aging on serum total and free testosterone levels in healthy men. Baltimore Longitudinal Study of Aging. J Clin Endocrinol Metab 86: 724-731.

4. Morley JE, Kaiser FE, Perry HM $3^{\text {rd }}$, et al, 1997 Longitudinal changes in testosterone, luteinizing hormone, and follicle-stimulating hormone in healthy older men. Metabolism 46: 410-413.

5. Wu FC, Tajar A, Pye SR, et al, 2008 Hypothalamicpituitary-testicular axis disruptions in older men are differentially linked to age and modifiable risk factors: the European Male Aging Study. J Clin Endocrinol Metab 93: 2737-2745.

6. Tajar A, Forti G, O’Neill TW, et al, 2010 Characteristics of secondary, primary, and compensated hypogonadism in aging men: evidence from the European Male Ageing Study. J Clin Endocrinol Metab 95: 1810-1818.

7. Buvat J, Maggi M, Guay A, Torres LO, 2013 Testosterone deficiency in men: systematic review and standard operating procedures for diagnosis and treatment. J Sex Med 10: 245-284.

8. Wang C, Nieschlag E, Swerdloff R, et al, 2009 Investigation, treatment and monitoring of late-onset hypogonadism in males. Int J Androl 32: 1-10.

9. Corona G, Rastrelli G, Vignozzi L, Mannucci E, Maggi M, 2012 How to recognize late-onset hypogonadism in men with sexual dysfunction. Asian J Androl 14: 251-259.

10. Corona G, Rastrelli G, Maggi M, 2013 Diagnosis and treatment of late-onset hypogonadism: systematic review and meta-analysis of TRT outcomes. Best Pract Res Clin Endocrinol Metab 27: 557-579.

11. Wu FC, Tajar A, Beynon JM, et al, 2010 Identification of late-onset hypogonadism in middle-aged and elderly men. N Engl J Med 363: 123-135.

12. Corona G, Mannucci E, Ricca V, et al, 2009 The agerelated decline of testosterone is associated with different specific symptoms and signs in patients with sexual dysfunction. Int J Androl 32: 720-728.

13. Corona G, Rastrelli G, Morelli A, Vignozzi L, Mannucci E, Maggi M, 2011 Hypogonadism and metabolic syndrome. J Endocrinol Invest 34: 557-567.

14. Kelly DM, Jones TH, 2015 Testosterone and obesity. Obes Rev 16: 581-606.

15. Corona G, Rastrelli G, Filippi S, Vignozzi L, Mannucci E, Maggi M, 2014 Erectile dysfunction and central obesity: an Italian perspective. Asian J Androl 16: 581-591.

16. Kaya E, Sikka SC, Gur S, 2015 A comprehensive review of metabolic syndrome affecting erectile dysfunction. J Sex Med 12: 856-875.

17. Vignozzi L, Filippi S, Comeglio P, et al, 2014 Nonalcoholic steatohepatitis as a novel player in metabolic syndrome-induced erectile dysfunction: an experimental study in the rabbit. Mol Cell Endocrinol 384: 143-154.

18. Corona G, Vignozzi L, Sforza A, Mannucci E, Maggi M, 2015 Obesity and late-onset hypogonadism. Mol Cell Endocrinol doi: 10.1016/j.mce.2015.06.031. [Epub ahead of print]

19. Corona G, Giorda CB, Cucinotta D, Guida P, Nada E; Gruppo di studio SUBITO-DE, 2014 Sexual dysfunction at the onset of type 2 diabetes: the interplay of depression, hormonal and cardiovascular factors. J Sex Med 11: 2065-2073.

20. Cheung KK, Luk AO, So WY, et al, 2015 Testosterone level in men with type 2 diabetes mellitus and related metabolic effects: A review of current evidence. J Diabetes Investig 6: 112-123.

21. Corona G, Monami M, Rastrelli G, et al, 2011 Type 2 diabetes mellitus and testosterone: a meta-analysis study. Int J Androl 34: 28-40.

22. Corona G, Monami M, Rastrelli G, et al, 2011 Testosterone and metabolic syndrome: a meta-analysis study. J Sex Med 8: 72-83.

23. Brand JS, Rovers MM, Yeap BB, et al, 2014 Testosterone, sex hormone-binding globulin and the metabolic syndrome in men: an individual participant data metaanalysis of observational studies. PLoS One 9: e100409.

24. Zumoff B, Strain GW, Miller LK, et al, 1990 Plasma free and non-sex-hormone-binding-globulin-bound testosterone are decreased in obese men in proportion to their degree of obesity. J Clin Endocrinol Metab 71: 929-931.

25. Corona G, Mannucci E, Fisher AD, et al, 2008 Low Levels of Androgens in Men with Erectile Dysfunction and Obesity. J Sex Med 5: 454-463.

26. Giagulli VA, Kaufman JM, Vermeulen A, 1994 Pathogenesis of the decreased androgen levels in obese men. J Clin Endocrinol Metab 79: 997-1000.

27. Vermeulen A, Kaufman JM, Deslypere JP, Thomas G, 1993 Attenuated luteinizing hormone (LH) pulse amplitude but normal LH pulse frequency, and its relation to plasma androgens in hypogonadism of obese men. J Clin Endocrinol Metab 76: 1140-1146.

28. Costanzo PR, Suárez SM, Scaglia HE, Zylbersztein C, Litwak LE, Knoblovits P, 2014 Evaluation of the hypothalamic-pituitary-gonadal axis in eugonadal men with type 2 diabetes mellitus. Andrology 2: 17-24.

29. Camacho EM, Huhtaniemi IT, O’Neill TW, et al, 2013 Age-associated changes in hypothalamic-pituitarytesticular function in middle-aged and older men are modified by weight change and lifestyle factors: longitudinal results from the European Male Ageing Study. Eur J Endocrinol 168: 445-455.

30. Maseroli E, Corona G, Rastrelli G, et al, 2015 Prevalence of endocrine and metabolic disorders in subjects with erectile dysfunction: a comparative study. J Sex Med 12: 956-965.

31. Rastrelli G, Carter EL, Ahern T, et al, 2015 Develop- 
ment of and Recovery from Secondary Hypogonadism in Ageing Men: Prospective Results from the EMAS. J Clin Endocrinol Metab100: 3172-3182.

32. Morelli A, Comeglio P, Sarchielli E, et al, 2013 Negative effects of high glucose exposure in human gonadotropinreleasing hormone neurons. Int J Endocrinol 2013: 684659 .

33. Morelli A, Sarchielli E, Comeglio P, et al, 2014 Metabolic syndrome induces inflammation and impairs gonadotropin-releasing hormone neurons in the preoptic area of the hypothalamus in rabbits. Mol Cell Endocrinol 382: 107-119.

34. Fernandez-Fernandez R, Martini AC, et al, 2006 Novel signals for the integration of energy balance and reproduction. Mol Cell Endocrinol 254-255: 127-132.

35. Loves S, de Jong J, van Sorge A, et al, 2013 Somatic and psychological effects of low-dose aromatase inhibition in men with obesity-related hypogonadotropic hypotestosteronemia. Eur J Endocrinol 169: 705-714.

36. Corona G, Rastrelli G, Monami M, et al, 2013 Body weight loss reverts obesity-associated hypogonadotropic hypogonadism: a systematic review and meta-analysis. Eur J Endocrinol 168: 829-843.

37. Dhindsa S, Furlanetto R, Vora M, et al, 2011 Low estradiol concentrations in men with subnormal testosterone concentrations and type 2 diabetes. Diabetes Care 34: 1854-1859.

38. Filippi S, Vignozzi L, Morelli A, et al, 2009 Testosterone partially ameliorates metabolic profile and erectile responsiveness to PDE5 inhibitors in an animal model of male metabolic syndrome. J Sex Med 6: 3274-3288.

39. Herde MK, Geist K, Campbell RA, Herbison AE, 2011 Gonadotropin-releasing hormone neurons extend complex highly branched dendritic trees outside the bloodbrain barrier. Endocrinology 152: 3832-3841.

40. Corona G and Maggi M, 2015 Perspective: regulatory agencies' changes to testosterone product labelling. J Sex Med 12: 1690-1693.

41. Singh R, Artaza JN, Taylor WE, et al, 2006 Testosterone inhibits adipogenic differentiation in 3T3-L1 cells: nuclear translocation of androgen receptor complex with beta-catenin and T-cell factor 4 may bypass canonical Wnt signaling to down-regulate adipogenic transcription factors. Endocrinology 147: 141-154.

42. Gupta V, Bhasin S, Guo W, et al, 2008 Effects of dihydrotestosterone on differentiation and proliferation of human mesenchymal stem cells and preadipocytes. Mol Cell Endocrinol 296: 32-40.

43. Maneschi E, Morelli A, Filippi S, et al, 2012 Testosterone treatment improbe metabolic syndrome-induced adipose tissue derangements. J Endocrinol 215: 347-362.

44. Maneschi E, Vignozzi L, Morelli A, et al, 2013 FXR activation normalizes insulin sensitivity in visceral preadipocytes of a rabbit model of MetS. J Endocrinol 218: $215-231$.

45. Tuomilehto J, Lindstrom J, Eriksson JG, et al, 2001
Prevention of type 2 diabetes mellitus by changes in lifestyle among subjects with impaired glucose tolerance. N Engl J Med 344: 1343-1350.

46. Pi-Sunyer X, Blackburn G, Brancati FL, et al, 2007 Look AHEAD Research Group. Reduction in weight and cardiovascular disease risk factors in individuals with type 2 diabetes: one-year results of the look AHEAD trial. Diabetes Care 30: 1374-1383.

47. Nathan DM, Buse JB, Davidson MB, et al, 2009 Medical Management of Hyperglycemia in Type 2 Diabetes: A Consensus Algorithm for the Initiation and Adjustment of Therapy: A Consensus Statement of the American Diabetes Association and the European Association for the Study of Diabetes. Diabetes Care 32: 193-203.

48. Knowler WC, Barrett-Connor E, Fowler SE, et al, 2002 Reduction in the incidence of type 2 diabetes with lifestyle intervention or metformin. N Engl J Med 346: 393-403.

49. Gillies CL, Abrams KR, Lambert PC, et al, 2007 Pharmacological and lifestyle interventions to prevent or delay type 2 diabetes in people with impaired glucose tolerance: systematic review and meta-analysis. BMJ 334: 299.

50. Biswas A, Oh PI, Faulkner GE, et al, 2015 Sedentary time and its association with risk for disease incidence, mortality, and hospitalization in adults: a systematic review and meta-analysis. Ann Intern Med 162: 123-132.

51. Ahtiainen JP, Nyman K, Huhtaniemi I, et al, 2015 Effects of resistance training on testosterone metabolism in younger and older men. Exp Gerontol 69: 148-158.

52. Maiorino MI, Bellastella G, Esposito K, 2015 Lifestyle modifications and erectile dysfunction: what can be expected? Asian J Androl 17: 5-10.

53. Gupta BP, Murad MH, Clifton MM, Prokop L, Nehra A, Kopecky SL, 2011 The effect of lifestyle modification and cardiovascular risk factor reduction on erectile dysfunction: a systematic review and meta-analysis. Arch Intern Med171: 1797-1803.

54. Buchwald H, Williams SE, 2004 Bariatric surgery worldwide 2003. Obes Surg 14: 1157-1164.

55. Vanstone M, Giacomini M, Smith A, Brundisini F, DeJean D, Winsor S, 2013 How diet modification challenges are magnified in vulnerable or marginalized people with diabetes and heart disease: a systematic review and qualitative meta-synthesis. Ont Health Technol Assess Ser 13: 1-40.

56. Saad F, Haider A, Doros G, Traish A, 2013 Long-term treatment of hypogonadal men with testosterone produces substantial and sustained weight loss. Obesity (Silver Spring) 21: 1975-1981.

57. Yassin DJ, Doros G, Hammerer PG, Yassin AA, 2014 Long-Term Testosterone Treatment in Elderly Men with Hypogonadism and Erectile Dysfunction Reduces Obesity Parameters and Improves Metabolic Syndrome and Health-Related Quality of Life. J Sex Med 11: 1567-1576. 
58. Zitzmann M, Saad F, Kliesch S, 2014 Long-term treatment with testosterone undecanoate injections leads to sustained weight loss and improvement of metabolic syndrome parameters in 381 hypogonadal men. J Sex Med 11: Suppl 1: 7.

59. Corona G, Rastrelli G, Maggi M, 2015 The pharmacotherapy of male hypogonadism besides androgens. Expert Opin Pharmacother 16: 369-387.

60. Corona G, Maseroli E, Maggi M, 2014 Injectable testosterone undecanoate for the treatment of hypogonadism. Expert Opin Pharmacother 15: 1903-1926.

61. Isidori AM, Balercia G, Calogero AE, et al, 2014 Outcomes of androgen replacement therapy in adult male hypogonadism: recommendations from the Italian society of endocrinology. J Endocrinol Invest 38: 103-112.

62. Corona G, Isidori AM, Buvat J, et al, 2014 Testosterone supplementation and sexual function: a meta-analysis study. J Sex Med 11: 1577-1592.

63. Corona G, Giagulli VA, Maseroli E, et al, 2015 Testosterone supplementation and body composition: results from a meta-analysis study. Eur J Endocrinol 2015 Nov 4. pii: EJE-15-0262. [Epub ahead of print]

64. Francomano D, Bruzziches R, Barbaro G, Lenzi A, Aversa A, 2014 Effects of testosterone undecanoate replacement and withdrawal on cardio-metabolic, hormonal and body composition outcomes in severely obese hypogonadal men: a pilot study. J Endocrinol Invest 37: 401-411.

65. Hildreth KL, Barry DW, Moreau KL, et al, 2013 Effects of testosterone and progressive resistance exercise in healthy, highly functioning older men with low-normal testosterone levels. J Clin Endocrinol Metab 98: 1891900 .

66. Hoyos CM, Yee BJ, Phillips CL, Machan EA, Grunstein RR, Liu PY, 2012 Body compositional and cardiometabolic effects of testosterone therapy in obese men with severe obstructive sleep apnoea: a randomised placebocontrolled trial. Eur J Endocrinol 167: 531-541.

67. Heufelder AE, Saad F, Bunck MC, Gooren L, 2009 Fifty-two-week treatment with diet and exercise plus transdermal testosterone reverses the metabolic syndrome and improves glycemic control in men with newly diagnosed type 2 diabetes and subnormal plasma testosterone. J Androl 30: 726-733.

68. Katznelson L, Robinson MW, Coyle CL, Lee H, Farrell CE, 2006 Effects of modest testosterone supplementation and exercise for 12 weeks on body composition and quality of life in elderly men. Eur J Endocrinol 155: 867-875.

69. Corona G, Fagioli G, Mannucci E, et al, 2008 Penile doppler ultrasound in patients with erectile dysfunction
(ED): role of peak systolic velocity measured in the flaccid state in predicting arteriogenic ED and silent coronary artery disease. J Sex Med 5: 2623-2634.

70. Isidori AM, Buvat J, Corona G, et al, 2014 A critical analysis of the role of testosterone in erectile function: from pathophysiology to treatment-a systematic review. Eur Urol 65: 99-112.

71. Corona G, Razzoli E, Forti G, Maggi M, 2008 The use of phosphodiesterase 5 inhibitors with concomitant medications. J Endocrinol Invest 31: 799-808.

72. Greco EA, Spera G, Aversa A, 2006 Combining testosterone and PDE5 inhibitors in erectile dysfunction: basic rationale and clinical evidence. Eur Urol 50: 940-947.

73. Aversa A, Isidori AM, Spera G, Lenzi A, Fabbri A. 2003 Androgens improve cavernous vasodilation and response to sildenafil in patients with erectile dysfunction. Clin Endocrinol (Oxf) 58: 632-638.

74. Shabsigh R, Kaufman JM, Steidle C, Padma-Nathan H, 2004 Randomized study of testosterone gel as adjunctive therapy to sildenafil in hypogonadal men with erectile dysfunction who do not respond to sildenafil alone. J Urol 172: 658-663.

75. Buvat J, Montorsi F, Maggi M, et al, 2011 Hypogonadal men non responders to the PDE5 inhibitor tadalafil benefit from normalization of testosterone levels with a $1 \%$ hydroalcoholic testosterone gel in the treatment of erectile dysfunction (TADTEST study). J Sex Med 8: 284-293.

76. Spitzer M, Basaria S, Travison TG, et al, 2012 Effect of testosterone replacement on response to sildenafil citrate in men with erectile dysfunction: a parallel, randomized trial. Ann Intern Med 157: 681-691.

77. Jannini EA, Screponi E, Carosa E, et al, 1999 Lack of sexual activity from erectile dysfunction is associated with a reversible reduction in serum testosterone. Int J Androl 22: 385-392.

78. Carosa E, Benvenga S, Trimarchi F, et al, 2002 Sexual inactivity results in reversible reduction of LH bioavailability. Int J Impot Res 14: 93-99.

79. Carosa E, Martini P, Brandetti F, et al, 2004 Type V phosphodiesterase inhibitor treatments for erectile dysfunction increase testosterone levels. Clin Endocrinol (Oxf) 61: 382-386.

80. Corona G, Mannucci E, Lotti F, et al, 2009 Impairment of couple relationship in male patients with sexual dysfunction is associated with overt hypogonadism. J Sex Med 6: 2591-2600.

81. Corona G, Rastrelli G, Monami M, et al, 2013 Frequency of sexual activity and cardiovascular risk in subjects with erectile dysfunction: cross-sectional and longitudinal analyses. Andrology 1: 864-871. 